\title{
Synthesis and Characterization of ZnO Nanopowders and ZnO-CNT Nanocomposites Prepared by Chemical Precipitation Route
}

\author{
D. GÜltekin*, M. Alaf And H. Akbulut \\ Engineering Faculty, Metallurgical \& Materials Engineering Department, Sakarya University \\ Esentepe Campus, 54187, Sakarya, Turkey
}

\begin{abstract}
The aims of this work are synthesis of $\mathrm{ZnO}$ nanopowders and producing nanocomposites by mixing with carbon nanotubes. $\mathrm{ZnO}$ nanopowders have been synthesized by chemical precipitation route. Different amount of collected nanosized Zn-based precipitates and chemically oxidized carbon nanotubes powder have been mix together and annealed at $400{ }^{\circ} \mathrm{C}$. Characterization of produced nanopowders and nanocomposites have been carried out by $\mathrm{X}$-ray diffractometer and scanning electron microscope.
\end{abstract}

DOI: $10.12693 /$ APhysPolA.123.274

PACS: 61.46.Df, 81.07.Wx, 81.05.Dz, 61.48.De, 81.20.Fw

\section{Introduction}

Zinc oxide $(\mathrm{ZnO})$ is an important material and has received considerable attention due to its applications in electrical, optical, mechanical, and scientific research. $\mathrm{ZnO}$ is a wide band gap $(3.37 \mathrm{eV})$ semiconductor and has a large binding energy $(60 \mathrm{meV})[1,2]$, low resistivity and high transparency in the visible range and high light trapping characteristics [3]. The synthesis of nanoparticles has become a highly developed field owing to the scientific and technological interest due to the structural peculiarities and unusual physical and chemical properties they may lead to [4]. In recent years, it has been found that $\mathrm{ZnO}$ can be synthesized by various routes such as electron beam evaporation technique [5], chemical spray pyrolysis technique [1], RF thermal plasma evaporation [6], sol-gel method [3, 7], and precipitation $[1,7]$ methods. Among these methods, precipitation has many advantages over the other methods, for example, it is unsophisticated and a low cost method. Moreover, the morphology of $\mathrm{ZnO}$ powders can be controlled easily by using an appropriate surfactant or capping agent such as polyethylene glycol, monoethanolamine (MEA), diethanolamine or triethanolamine [7].

Over the past few years, great efforts have been made toward the syntheses of nanocomposites of inorganic materials and carbon nanotubes (CNT) [8] with the aim of exploiting the unique properties of CNTs (such as a high theoretical electrical conductivity, high aspect ratio, remarkable thermal conductivity, and good mechanical properties) [9]. In this work, $\mathrm{ZnO}$ nano powders and $\mathrm{ZnO} /$ multi-walled $\mathrm{CNT}$ ( $\mathrm{ZnO} / \mathrm{MWCNT}$ ) nano-composites were synthesized and characterized.

\footnotetext{
* corresponding author
}

\section{Experimental}

Figure 1 represents the process flow chart used for synthesis of nanostructured $\mathrm{ZnO}$ powders by homogeneous precipitation and producing of $\mathrm{ZnO} / \mathrm{MWCNT}$ nanocomposites. Zinc acetate dihydrate $\left(\mathrm{Zn}\left(\mathrm{CH}_{3} \mathrm{COO}\right)_{2} \cdot 2 \mathrm{H}_{2} \mathrm{O}\right)$ (Merck) was used as a precursor whereas distilled water was used as solvents. Monoethanolamine (MEA) (Merck) was used for adjusting of sol $\mathrm{pH}$. MEA was added to homogeneous and transparent solution until white precipitates are obtained. The $\mathrm{pH}$ value was recorded as 10 . The addition of MEA changes the alkaline nature of the prepared sols that give $\mathrm{ZnO}$ films with improved crystalline quality [10]. After the precipitation, collected nanosized powders were dried at $100^{\circ} \mathrm{C}$.

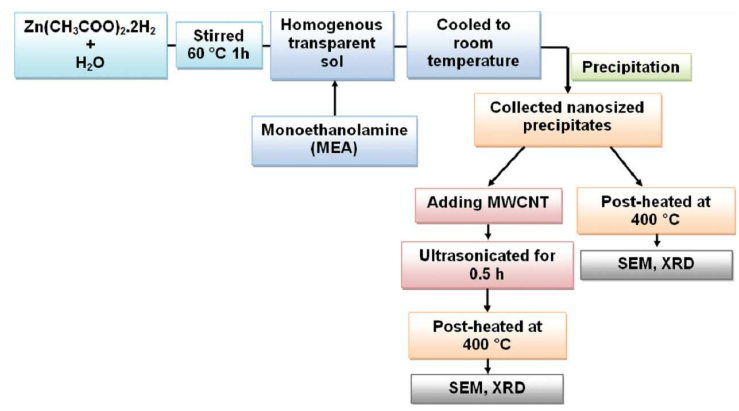

Fig. 1. The process flow chart used for synthesis of nanostructured $\mathrm{ZnO}$ and $\mathrm{ZnO} / \mathrm{MWCNT}$ nanocomposite.

MWCNTs of over $10 \mathrm{~lm}$ in length with outer diameters of $50 \mathrm{~nm}$ were purchased from Arry Nano. In order to eliminate ofamorphous carbon and remove impurities, MWCNTs were annealed to $350{ }^{\circ} \mathrm{C}$ and then treated with hydrochloric acid for one hour. Chemical oxidation of CNTs was carried out with a mixture of sulphuric acid and nitric acid in ratio $3: 1$ for $3 \mathrm{~h}$. In order to enhance the efficiency, it is necessary to attach other substances 
to the surface of MWCNTs. Therefore, the surface modification of MWCNTs has been a focus of many environmental scientists [11].

An appropriate amount of $\mathrm{ZnO}$ nanopowders and functionalized MWCNTs $(\mathrm{ZnO} / \mathrm{MWCNT}$ ratios are 5:1 and $2: 1$, respectively) were first dispersed into water by magnetic stirrer and ultrasonicated for $30 \mathrm{~min}$ to form a well dispersed. Since the boiling point of MEA and the thermal decomposition temperature of zinc acetate dihydrate are 170 and $240^{\circ} \mathrm{C}$, respectively, a heat treatment temperature of $300{ }^{\circ} \mathrm{C}$ is sufficient for the complete evaporation of organics and to initiate the process of formation and crystallization of the $\mathrm{ZnO}$ film [10] fabricated coatings annealed at $400^{\circ} \mathrm{C}$.

\section{Results and discussions}

The formation of $\mathrm{ZnO}$ particles from the hydrolysis of $\mathrm{Zn}^{2+}$ ions in aqueous media is known to be a complex process. Many polyvalent cationic species can be formed between $\mathrm{Zn}^{2+}$ ions with $\mathrm{OH}^{-}$ions and are strongly dependent upon the $\mathrm{pH}$ of the solution. However, the precipitation of $\mathrm{ZnO}$ particles has been usually described through a growth unit that might be either $\mathrm{Zn}(\mathrm{OH})_{2}$ or $\mathrm{Zn}(\mathrm{OH})_{4}^{2-}$ ions depending on the $\mathrm{pH}$, temperature, and synthetic methods. The growth of $\mathrm{ZnO}$ from $\mathrm{Zn}(\mathrm{OH})_{2}$ has been usually suggested to occur through the dissolution-reprecipitation mechanism [12]. $\mathrm{ZnO}$ will be formed through the chemical reaction [10]: $\mathrm{Zn}(\mathrm{OH})_{2} \rightarrow \mathrm{ZnO}+\mathrm{H}_{2} \mathrm{O}$.

Figure 2 presents the X-ray diffraction (XRD) patterns of synthesized powder and nanocomposites. The peak positions in each product agree well with the reflections of bulk $\mathrm{ZnO}$ and $\mathrm{ZnO} / \mathrm{CNT}$ composites with all peaks corresponding well to standard crystallographic data ( $\mathrm{ZnO}$ : JCPDS 01-076-0704, C: JCPDS No. 00-026-1080). As could be seen from the XRD patterns, all products have polycrystalline nature and peaks belonging to the (100), (002), (101) (102), (110), (103), (112) and (201) reflections were seen in $\mathrm{ZnO}$ powders, also (002) reflection for $\mathrm{C}$. No other peak related to impurities was detected in the spectrum, which further confirms that the synthesized products are of high purity. The $\mathrm{ZnO}$ powders show a highly oriented (101), (100) and (002) peaks, respectively. Although it was obtained that there has been slight changing in orientation and peak intensities with an increasing amount of CNT.

TABLE

XRD diffraction peaks information $2 \Theta$ of $\mathrm{ZnO}$ and $\mathrm{ZnO}$ CNT nanocomposites.

\begin{tabular}{c|c|c|c}
\hline \hline$(h k l)$ & ZnO & ZnO/CNT 5:1) & ZnO/CNT 2:1) \\
\hline$(100)$ & 31.680 & 31.680 & 31.680 \\
$(002)$ & 34.320 & 34.339 & 34.380 \\
$(101)$ & 36.160 & 36.158 & 36.141
\end{tabular}

As could be seen in Table, the XRD peaks shifting of $\mathrm{ZnO}$ and $\mathrm{ZnO} / \mathrm{MWCNT}$ nanocomposites were investigated and reveal the effect of the amount of CNT. It

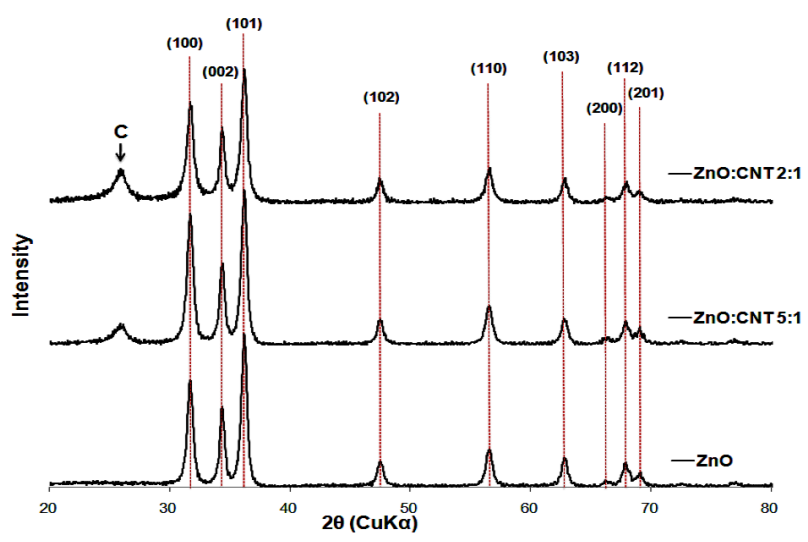

Fig. 2. The XRD diffraction patterns of $\mathrm{ZnO}$ and $\mathrm{ZnO} / \mathrm{MWCNT}$ products.

was observed that there have been slight increases/decreases between XRD peaks angle belonging to $\mathrm{ZnO}$ and $\mathrm{ZnO} / \mathrm{MWCNT}$ nanocomposites. While a peak was observed at $34.320^{\circ}$ from the XRD $2 \theta$ scan data of the pure $\mathrm{ZnO}$ nanopowders corresponding to $\mathrm{ZnO}$ (002), $\mathrm{ZnO} /$ MWCNT nanocomposites resulted in shifting XRD peaks to a higher angle. Furthermore, ZnO/MWCNT (5:1) and $\mathrm{ZnO} / \mathrm{MWCNT}(2: 1)$ nanocomposites peak shifts to $36.158^{\circ}$, and $36.141^{\circ}$, respectively. The peak shift in the XRD curves originates from difference between $\mathrm{ZnO}$ and $\mathrm{ZnO} / \mathrm{MWCNT}$ lattice constants. These peaks shifts may indicate a lattice strain between $\mathrm{ZnO}$ and CNTs.

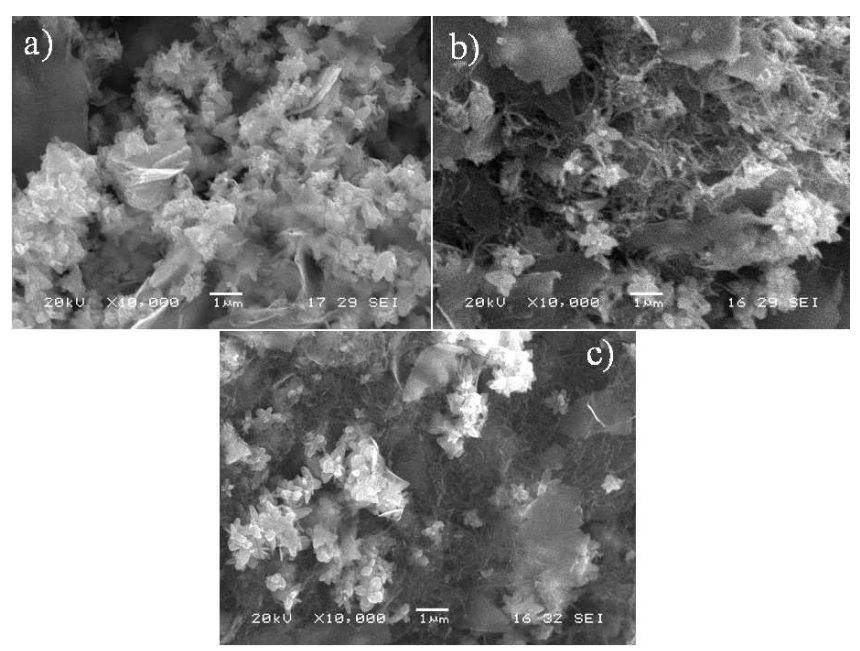

Fig. 3. SEM micrographs of (a) $\mathrm{ZnO}$, (b) $\mathrm{ZnO} / \mathrm{CNT}$ 5:1, (c) $\mathrm{ZnO} / \mathrm{CNT} 2: 1$.

Grain morphologies of $\mathrm{ZnO}$ powders can be observed from SEM images represented in Fig. 3. The grain sizes of the $\mathrm{ZnO}$ powders were calculated by using Scherrer's formula and the crystallite size is $26 \mathrm{~nm}$. In the literature, $\mathrm{ZnO}$ nanostructures having 9-250 nm have been reported [13]. The nanostructure has both approximately $0.1-1 \mu \mathrm{m}$ sized agglomerated nanoparticles and 
prism-like nanoflowers. It was observed that nanocomposite structures have well-dispersed carbon nanotubes network.

\section{Conclusions}

Polycrystalline and nanostructured $\mathrm{ZnO}$ powders were successfully produced by homogeneous precipitation route, then $\mathrm{ZnO} / \mathrm{MWCNT}$ nanocomposites were prepared by physically mixing with nanopowders. The effects of amount of CNT on the properties of powders have been presented. The XRD patterns of all products were of polycrystalline nature. Experimental results showed that although the crystal orientations and particle sizes of the prepared $\mathrm{ZnO}$ particles were not affected with amount of CNT, slight increases/decreases in XRD peaks angle were observed. The intensity of the (101) orientation is predominant for $\mathrm{ZnO}$ and $\mathrm{ZnO} / \mathrm{MWCNT}$ products. $\mathrm{ZnO}$ nanoparticles and CNTs combined together and results showed that $\mathrm{ZnO}$ and nanotubes kept their structure and formed a nanocomposite. $\mathrm{ZnO}$ and nanotubes have not reacted with each other.

\section{Acknowledgments}

The authors would like to acknowledge the financal support of Sakarya University, Coordination of Scientific Research Project (BAPK) under the contract number 2009-50-02-023.

\section{References}

[1] B.B. Rao, Mater. Chem. Phys. 64, 62 (2000).

[2] S. Ilican, Y. Caglar, M. Caglar, F. Yakuphanoglu, Appl. Surf. Sci. 255, 2353 (2008).

[3] Y. Caglar, S. Ilican, M. Caglar, F. Yakuphanoglu, Spectrochim. Acta A 67, 1113 (2007)

[4] C.A. Ibarguen, A. Mosquera, R. Parra, M.S. Castro, J.E. Rodriguez-Paez, Mater. Chem. Phys. 101, 433 (2007)

[5] D.R. Sahu, S.Y. Lin, J.L. Huang, Microelectr. J. 38, 245 (2007)

[6] J. Tsujinoa, N. Homma, T. Sugawara, I. Shimono, Y. Abe, Thin Solid Films 407, 86 (2002).

[7] S. Suwanboon, P. Amornpitoksuk, N. Muensit, $C e-$ ram. Int. 37, 2247 (2011)

[8] J. Yu, J. Fan, B. Cheng, J. Power Sources 196, 7891 (2011)

[9] L.S. Ying, M.A.M. Salleh, H.M. Yusoff, S.B.A. Rashid, J. Razak, J. Industr. Eng. Chem. 17, 367 (2011)

[10] P. Sagar, P.K. Shishodia, R.M. Mehra, Appl. Surf. Sci. 253, 5419 (2007)

[11] T.A. Saleh, M.A. Gondal, Q.A. Drmosh, Z.H. Yamani, A. Al-Yamani, Chem. Eng. J. 166, 407 (2011)

[12] N. Samaele, P. Amornpitoksuk, S. Suwanboon, Powder Technol. 203, 243 (2010).

[13] Y.S. Kim, W.P. Tai, S.J. Shu, Thin Solid Films 491, $153(2005)$ 